\title{
Coupled modeling of a District Heating System with Aquifer Thermal Energy Storage and Absorption Heat Transformer
}

\author{
Carles Ribas Tugores ${ }^{1} \quad$ Henning Francke ${ }^{2}$ Falk Cudok ${ }^{3}$ \\ Alexander Inderfurth ${ }^{1} \quad$ Stefan Kranz ${ }^{2} \quad$ Christoph Nytsch-Geusen ${ }^{1}$ \\ ${ }^{1}$ Fachgebiet für Versorgungsplanung und Versorgungstechnik, Berlin University of the Arts, Germany, \\ \{c.ribastugores, a. inderfurth\}@udk-berlin.de \\ ${ }^{2}$ Helmholtz Centre Potsdam - GFZ German Research Centre for Geosciences, \\ $\{$ kranz, francke\} @gfz-potsdam.de \\ ${ }^{3}$ Institute of Energy Engineering, Technische Universität Berlin, Germany, falk . cudok@tu-berlin. de
}

\begin{abstract}
Aquifer thermal energy storages (ATES) are a promising technology for seasonal thermal energy storage which can bridge the gap between constant production and seasonally varying demand. This paper presents first simulation results of an energy concept proposed for the university campus BerlinCharlottenburg, which is characterized by the combination of an ATES system as a seasonal thermal energy storage and an absorption heat transformer (AHT), which supplies 50 buildings of the campus with heating energy. Furthermore, the paper deals with the modeling of the different subsystems, described in Modelica; energy production, storage, consumption and distribution and their integration in a coupled Modelica system model.
\end{abstract}

Keywords: Modelica, ATES, geothermal, absorption heat transformer, district heating, FVM

\section{Introduction}

Some thermal energy systems such as the ones including combined heat and power plants (CHP), which provide electrical base loads or solar thermal energy show a strong time mismatch between consumption and production. This mismatch can be compensated by the addition of a thermal energy storage (TES) to the system (see Figure 1).

The selection of a TES mainly depends on the required storage period, the economic viability and the operating condition (Dinçer \& Rosen 2002). Among the possibilities for low-medium temperatures $\left(10 \ldots 90^{\circ} \mathrm{C}\right)$, the sensible heat storage tank with water is the most common choice (Dinçer \& Rosen 2002). This is mainly due to their simplicity, low cost, good performance and the favorable thermal properties of water, namely high specific heat capacity and relative high density. However, this solution is designed to compensate the daily variation. If seasonal variations are to be compensated, a larger storage is needed. In this scenario the utilization of natural aquifers as seasonal thermal energy storage (ATES) is an interesting possibility with low cost in relation to its high storage capacity.

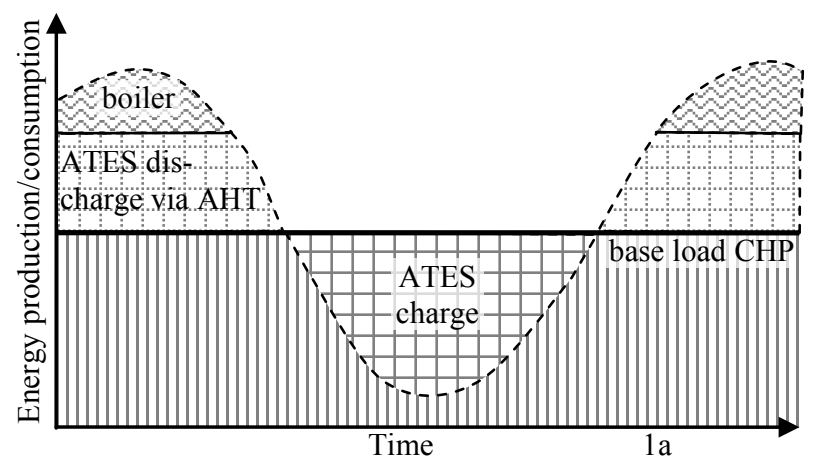

Figure 1. Seasonally fluctuating energy demand (dashed) covered by combined heat and power plant (CHP, solid) and previously stored CHP surplus recovered from aquifer thermal energy storage (ATES), topped up by a boiler.

An ATES uses groundwater in an aquifer to store thermal energy for several months, mainly for heating and cooling of buildings. The aquifer is an underground layer where water can flow through the permeable material. Common ATES systems consist of two wells (or well groups), a cold well and a warm well. When charging the ATES system with heat, groundwater is produced from the cold well, heated up and re-injected into the aquifer through the warm well. To discharge the ATES, the flow direction of water is reversed and heat is extracted (see Figure 2). The heat is typically recovered at a temperature lower than the original injection temperature due to heat exchange with the porous matrix and adjacent layers.

In order to avoid triggering the precipitation of dissolved minerals and potentially reducing aquifer permeability, the injection temperature should be kept below a certain limit $T_{\mathrm{inj}}^{\max }$, which depends on the fluid chemistry. This upper temperature limit does not always meet the requirements of the consumers, 
making it necessary to raise the temperature to suitable temperatures for the existing heating systems. In this regard the absorption heat transformer (AHT) is an appropriate technological solution that is able to use thermal energy at an intermediate temperature level to heat a fluid at a high temperature level.

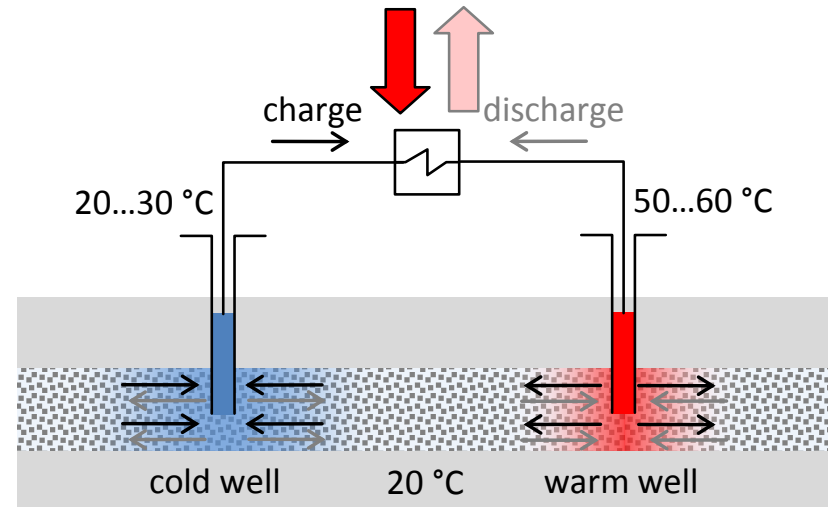

Figure 2. ATES principle with two wells.

The ATES technology has already been implemented in several projects such as in Rostock (Schmidt et al. 2000 ) or the German parliament buildings in Berlin (Sanner et al. 2005). There is, however, still potential to improve this technology itself as well as a need to investigate its match with other thermal technologies. Hence, the main goal of the joint project "Efficiency and reliability of energy systems in urban districts with seasonal energy storage in aquifers", is the development of a design concept, regardless of location, that assists the designer in the implementation of feasible and efficient ATES systems.

This paper presents the first results of the simulations of an energy concept proposed for the university campus Berlin-Charlottenburg and a brief description of the implemented models in Modelica. The main feature of the system is the combination of an ATES system as a seasonal thermal energy storage with an AHT.

\subsection{Joint Project}

The interdisciplinarity of the topic requires the participation of different research groups. Research groups from Helmholtz Centre Potsdam - GFZ German Research Centre for Geosciences (GFZ), Technische Universität Berlin (TUB) and Berlin University of the Arts (UdKB) are involved in the project in order to properly cover its different aspects.

The International Centre for Geothermal Research at GFZ covers research in a holistic approach along the whole chain of geothermal technologies from the geothermal reservoir to the provision of power, heat, and chill. One part of this work deals with simulation, evaluation and design of ATES systems.

At the department of Energy Engineering of TUB the work focuses on the development of an absorption device, which features a great flexibility in terms of operating modes. It can work as absorption heat pump, absorption chiller (heat pump type I) or absorption heat transformer (heat pump type II). For that purpose, an experimental set-up is currently being installed that allows a better understanding of this technology. Furthermore, theoretical models of this absorption device are implemented in Modelica and presented here.

At the research group of UdKB the focus is on the energy consumption of urban districts, the energy supply systems and the provision with renewable energy. One main task is the development of a method to model a whole district, including buildings and installations, renewable energy production, as well as the distribution networks for cooling and heating, with strongly simplified low-order building models that allow to study such complex systems with low computational effort.

Besides the tasks described above, all project partners collaborate on the presented case study, the university campus Berlin-Charlottenburg, which on one hand serves to face the challenges of a real-world project, such as the data collection related to the buildings and the obtainment of a drilling license. On the other hand, different energy concepts can be studied based on a realistic scenario.

\subsection{Energy Concept}

From a thermal point of view, the presented system can be divided into three temperature ranges, at which the different subsystems either extract or inject heat: high temperature (above $70{ }^{\circ} \mathrm{C}$ ), intermediate temperature (between 40 and $70{ }^{\circ} \mathrm{C}$ ) and ambient temperature (see Figure 3). Thermal energy at the high temperature range is produced by combined heat and power plants (CHP), boilers and the AHT. This thermal energy is used to supply the buildings via a district heating network (DHN). The intermediate temperature range includes the hot well of the aquifer and the return temperature of the DHN.

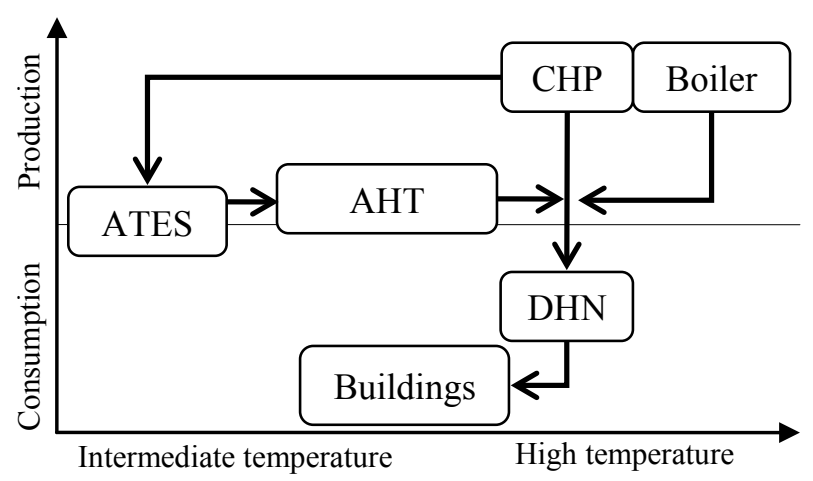

Figure 3. Energy concept schema with main thermal energy flows.

The system works as sketched in Figure 1 and Figure 3. The CHP produces a constant amount of energy to 
cover the electric base load of the district. Its thermal energy is used to supply the buildings. In case there is a surplus of thermal energy, i.e., the amount of produced thermal energy is higher than the current demand of the DHN, this energy is used to charge the aquifer. If the thermal energy produced by the CHP does not cover the heat demand of the buildings, then, if available, thermal energy will be drawn from the aquifer. This heat energy then powers the AHT. In case the thus supplied thermal energy is still insufficient, either because of the limited capacity of the AHT or the depletion of the ATES (production temperature below minimum usable temperature), a boiler covers the remaining demand gap.

\section{Modeling}

The university campus Berlin-Charlottenburg is used as a case study for developing the modeling approach. In a first step, a model with simplified components and boundary conditions was developed in order to investigate the interaction of the sub-models.

The system model is assembled from component models from the MSL - Modelica Standard Library (Modelica-Association 2014), the Annex60 library (Wetter \& Treeck 2014), the BuildingSystems library (Nytsch-Geusen 2014) and models specifically implemented for this project. The used models from the different libraries has fluid ports and input/output connectors as interfaces. Fluid ports are used to connect models mimicking the hydraulics of the real system while input and output connectors are mainly used for control signals.

The following subsections explain the overall system and its subsystems in more detail.

\subsection{Overall System}

Figure 4 shows the hydraulic configuration of the Modelica model, with dashed and solid lines representing heat and mass flows, respectively. At the left and mid side of the diagram there is the thermal energy production system, composed by several production units, CHP, boiler and AHT, as well as per the seasonal thermal energy storage, ATES. At the very right side of the diagram there is the main consumption system, the building model, and its interface to the thermal energy production system, the DHN. The main components are either connected directly or via heat exchangers (HXs).

The control strategy of the model is explained below with help of Figure 4.

$\dot{m}_{\text {boiler, }}$, the mass flow rate through the boiler and $\mathrm{HX}_{3}$ is adjusted by a PI controller so that the DHN can extract the required energy in order to raise the supply mass flow rate, $\dot{m}_{\mathrm{DHN}}$, to a certain set temperature. In this simulation it is set to a constant value of $90^{\circ} \mathrm{C}$.

The CHP model calculates, according to its inlet temperature and its constant heat production rate, the exact mass flow rate $\dot{m}_{\text {CHP }}$ that can be heated up to a set temperature. In this simulation it is set to a constant value of $95^{\circ} \mathrm{C}$.

Taking into account that the boiler and CHP has the same set temperature, then, if the mass flow rate in the CHP $\dot{m}_{\mathrm{CHP}}$ is higher than the mass flow rate flowing through the boiler $\dot{m}_{\text {boiler }}$ (used to heat up the DHN), more energy is produced by the CHP than requested by the DHN. In this case, the excess part of $\dot{m}_{\mathrm{CHP}}$, which is not needed to heat the DHN ( $\dot{m}_{\text {surplus }}=\dot{m}_{\mathrm{CHP}}-$ $\dot{m}_{\text {boiler }}$ and $\dot{m}_{\mathrm{T} 2}=0$ ), is used to charge the aquifer $\left(\dot{m}_{\text {charge }}>0\right)$. In the opposite case the mass flow rate requested by the CHP is lower than the one requested to heat up the DHN ( $\left.\dot{m}_{\mathrm{CHP}}<\dot{m}_{\text {boiler }}\right)$, the mass flow rate leaving the heat exchanger of the DHN $\dot{m}_{\text {boiler }}$ is split, one fraction goes to the CHP, $\dot{m}_{\mathrm{CHP}}$, and the rest flows through the parallel branch, which is connected to the AHT $\left(\dot{m}_{\mathrm{T} 2}=\dot{m}_{\text {boiler }}-\dot{m}_{\mathrm{CHP}}\right.$ and $\dot{m}_{\text {surplus }}=$ $0)$.

In this case, the AHT is switched on given that two conditions are fulfilled. A minimum mass flow rate

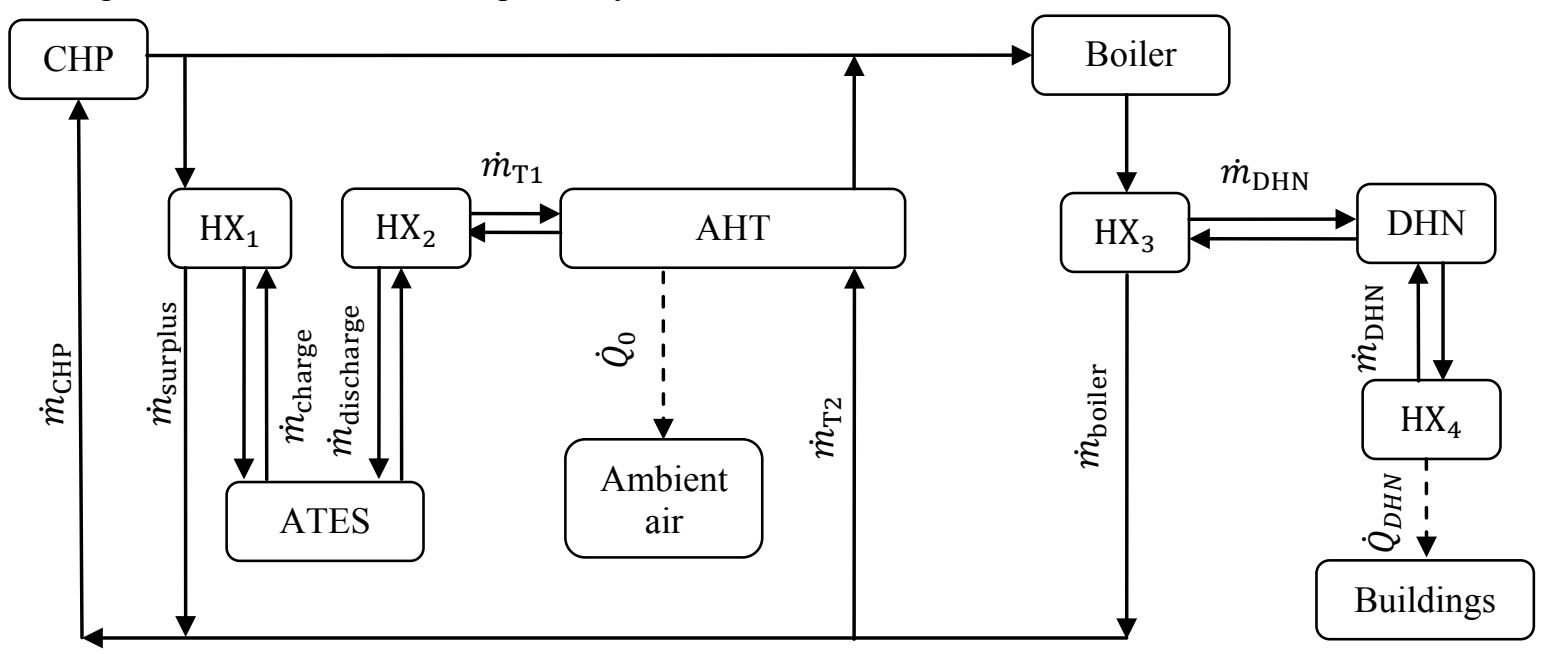

Figure 4. System schema of the Modelica model with main mass (solid) and thermal energy (dashed) flows. 
$\dot{m}_{\mathrm{T} 2}$ and a minimum characteristic temperature difference $\Delta \Delta T$ (see 2.4). These conditions are not fulfilled when the ATES temperature is too low or when the ambient temperature limiting $T_{0}$ is too high. During the operation of the AHT energy is extracted from the ATES and used to drive the AHT ( $\dot{m}_{\text {discharge }}>0$ and $\dot{m}_{\mathrm{T} 1}>0$ ).

\subsection{Combined Heat and Power Plant and Boiler}

Boiler and CHP are represented by simple models, because the major interest of the simulation lies on ATES, AHT, DHN and buildings as thermal consumers.

The CHP works under stationary conditions and can be therefore considered as a constant heat source. The CHP is modeled with a prescribed heat flow. Assuming an electrical output of the CHP to cover the electric base load of $10 \mathrm{MW}$ and a CHP ratio electricity/heat of 0.6 leads to a constant heat production rate of $15 \mathrm{MW}$.

The boiler's task is to ensure that the buildings' heat demand is fulfilled. We neglect any limitations and assume that this is always achieved. The boiler is modeled with a prescribed output temperature. The boiler's power is not limited and its output temperature is set to $95^{\circ} \mathrm{C}$.

\subsection{Aquifer Thermal Energy Storage}

The ATES model consists of two well models coupled by the produced/injected flow. This flow is heated or cooled in a heat exchanger which connects the ATES with the energy system. Both sides of the heat exchanger have equal mass flow rates. Well mass flow can be increased via a bypass in order to limit the injection temperature to $T_{\mathrm{inj}}^{\max }$. In the presented scenario we assume $T_{\mathrm{inj}}^{\max }=60^{\circ} \mathrm{C}$. In reality, well mass flow rate is limited by friction pressure losses in the well and in the aquifer with being a function of well diameter and rock permeability. However, as pressure loss is not considered here, well mass flow rate is limited by a prescribed value, representing the storage size together with the aquifer thickness.

The aquifer around the wells is modeled as two independent radially symmetric discs or rings with an inner radius $r_{\text {if }}$ (interface well/aquifer) and an outer diameter $r_{\infty}$. They are thermally insulated in the vertical direction. Thermodynamic equilibrium between rock and fluid, i.e., a common temperature is assumed. Eq. (1), the $\mathrm{PDE}^{1}$ for convective-conductive transient radial heat flow in porous media (Bear \& Bachmat 1990) written in polar coordinates provides the temperature $T(r, t)$ for a given Darcy flux, which is determined by the radial distribution of the mass flow entering/leaving the well $\dot{m}$ as $u(r)=\frac{\dot{m}}{\rho^{f_{2}} \pi r H}$.

\footnotetext{
${ }^{1}$ partial differential equation
}

$$
\rho c_{p} \frac{\partial \mathrm{T}}{\partial \mathrm{t}}=\frac{1}{r} \frac{\partial}{\partial r} k_{\mathrm{eff}} r \frac{\partial T}{\partial r}-\rho^{\mathrm{f}} u c_{p}^{\mathrm{f}} \frac{\partial T}{\partial r}
$$

$H$ is the thickness of the aquifer. The effective thermal conductivity $k_{\text {eff }}$ is calculated from the thermal conductivity of the rock $k$ and the dispersion length $D$ :

$$
k_{\text {eff }}=k+D|u| c_{p}^{\mathrm{f}} \rho^{\mathrm{f}}
$$

$\bar{\rho}$ is the bulk density, the average of fluid density $\rho^{\mathrm{f}}$ and rock density $\rho^{\mathrm{s}}$, weighted with their respective volume fraction. The specific bulk heat capacity $\overline{c_{p}}$ is calculated likewise.

$$
\begin{aligned}
\bar{\rho} & =P \cdot \rho^{\mathrm{s}}+(1-P) \cdot \rho^{\mathrm{s}} \\
\overline{c_{p}} & =P \cdot c_{p}^{\mathrm{f}}+(1-P) \cdot c_{p}^{\mathrm{s}}
\end{aligned}
$$

At the outer boundary temperature is kept at the domain's initial value $T_{\infty}$ :

$$
\begin{gathered}
T(r, t=0)=T_{\infty} \\
T\left(r=r_{\infty}, t\right)=T_{\infty}
\end{gathered}
$$

$r_{\infty}$ is set to a large value so that the boundary is outside of the thermally influenced region. To verify this condition eq. (7) is monitored by an assert statement:

$$
\left.\frac{\partial T}{\partial r}\right|_{r_{\infty}}=0
$$

At the inner boundary temperature is set to injection temperature during injection or else heat flow is set to zero.

$$
\begin{array}{lc}
T\left(r_{\mathrm{if}}\right)=T_{\mathrm{inj}} & \text { during injection } \\
\left.\frac{\partial T}{\partial r}\right|_{r_{\mathrm{if}}}=0 & \text { else }
\end{array}
$$

The PDE is solved on the spatially discretized 1D domain using the FVM method (see Appendix).

The aquifer model has been successfully validated against a 3D FEM model simulated in COMSOL.

The aquifer model parameters are given in Table 1. Water properties are provided by the MSL.

Table 1. Aquifer model parameters

\begin{tabular}{llr}
\hline$H$ & thickness & $10 \mathrm{~m}$ \\
& initial temperature & $20^{\circ} \mathrm{C}$ \\
$\rho_{\text {rock }}$ & rock density & $2650 \mathrm{~kg} / \mathrm{m}^{3}$ \\
$k$ & rock thermal conductivity & $3 \mathrm{~W} /(\mathrm{m} \cdot \mathrm{K})$ \\
$c_{\mathrm{p}, \text { rock }}$ & rock specific heat capacity & $800 \mathrm{~J} /(\mathrm{kg} \cdot \mathrm{K})$ \\
$P$ & porosity & 0.3 \\
$r_{\text {if }}$ & radius interface well/aquifer & $0.1 \mathrm{~m}$ \\
$r_{\infty}$ & radius of outer boundary & $200 \mathrm{~m}$ \\
\hline
\end{tabular}

\subsection{Absorption Heat Transformer}

The AHT is a thermally driven heat pump of type II, which splits a heat flow at intermediate temperature level in two heat flows at high and low temperature levels (see Figure 5). The gain of the AHT is the output heat flow $\dot{Q}_{2}$ at the high temperature level $T_{2}$. The effort is the driving heat flow $\dot{Q}_{1}$ at the intermediate 
temperature level $T_{1}$ (equation (13)). With this device it is possible to provide heat for heating (e.g. the district) at $T_{2}$ driven by heat from the ATES at $T_{1}$ without using additional energy.

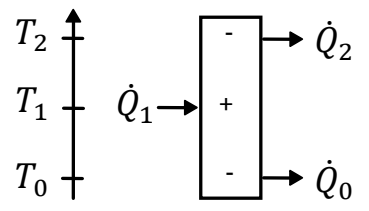

Figure 5. Black box scheme of an absorption heat transformer (Heat flows at different temperature levels).

The AHT is modeled following the steady-state approach of the characteristic equation. This approach was often applied and explained by absorption chiller (Albers et al. 2008; Puig-Arnavat et al. 2010). Cudok $\&$ Ziegler (2015) discuss the method of the characteristic equation for general apply to AHT and absorption heat pump (type I) and chiller.

The heat flows $\dot{Q}_{0}$ and $\dot{Q}_{2}$ are described by the characteristic temperature difference $\Delta \Delta T$ or respective the temperatures levels $T_{2}, T_{1}$ and $T_{0}$. The heat flow $\dot{Q}_{1}$ results from the energy balance eq. (12). To define a concrete AHT device the parameters, $\mathrm{s}_{2}, \mathrm{~s}_{0}, \Delta \Delta T_{\min , 2}$, $\Delta \Delta T_{\min , 0}$ and $B$ are needed.

$$
\begin{gathered}
\Delta \Delta T=B \cdot\left(T_{1}-T_{0}\right)-\left(T_{2}-T_{1}\right) \\
\dot{Q}_{2}=s_{2} \cdot\left(\Delta \Delta T-\Delta \Delta T_{\min , 2}\right) \\
\dot{Q}_{0}=s_{0} \cdot\left(\Delta \Delta T-\Delta \Delta T_{\min , 0}\right) \\
\dot{Q}_{1}=\dot{Q}_{0}+\dot{Q}_{2} \\
\operatorname{COP}=\frac{\dot{Q}_{2}}{\dot{Q}_{1}}
\end{gathered}
$$

The AHT switches off when the characteristic temperature difference $\Delta \Delta T$ drops below a minimum value chosen to prevent the model from leaving the valid operating range, here this minimum value is set to $3 \mathrm{~K}$, or when the mass flow rate $\dot{m}_{\mathrm{AHT}}$ is lower than a minimum value. This minimum mass flow rate is determined by the available gain heat flow $\dot{Q}_{2}$ of the AHT (equation (10)) and the assumed condition of a maximal temperature rise, which value set to $15 \mathrm{~K}$ is added to ensure normal operating conditions for the AHT. To switch off the device it is bypassed.

The AHT is controlled by the mean temperature at the low temperature level $T_{0}$ (equation (9)), which is variable but limited by the current ambient temperature.

For the system simulation the AHT is parameterized in such a way that it has a nominal power of $2 \mathrm{MW}$ under the following operating conditions; $T_{2}=75^{\circ} \mathrm{C}$, $T_{1}=60{ }^{\circ} \mathrm{C}, T_{0}=5{ }^{\circ} \mathrm{C}$.

\subsection{Buildings}

For use in the system model the approx. 50 buildings of the university campus Berlin-Charlottenburg with a total of $434020 \mathrm{~m}^{2}$ heated floor space are aggregated into one substitute building model to ensure fast computation times of this component (see Figure 6).

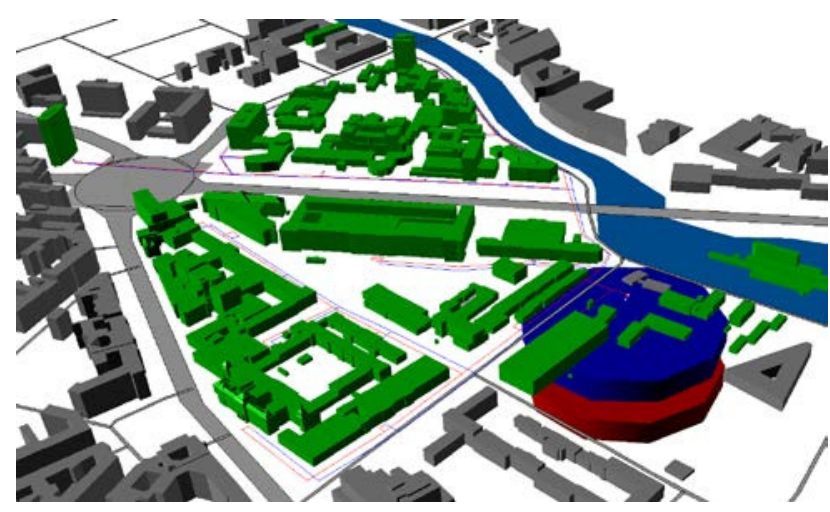

Figure 6. Building stock of the university campus BerlinCharlottenburg (green), which is aggregated in one substitute building model. The blue and red cylinder indicate a possible location for the ATES.

The aggregation is done via a parameter identification method that uses optimization strategies, described in (Inderfurth et al. 2015). This method takes measured heat consumption data of all considered buildings into account. By repeated simulation of the substitute building model and comparing simulated and measured consumption important parameters like thermal capacities, thermal transmittances, window areas, etc. are gradually fitted to the building model. This process ensures that the substitute model together with its fitted parameter set accurately represents the thermal characteristic of the city district. The underlying loworder building model consists of four thermal capacities (internal capacities, external wall, base plate and room air), four window models to account for solar heat gains, several wall constructions, air change with the building's environment and an internal heat source accounting for internal heat gains through electrical consumption. All component models are provided by the BuildingSystems library for building performance simulation (Nytsch-Geusen 2014).

The low-order building model calculates the ideal, instantaneous heating demand of the aggregated buildings by calculating heat gains and losses to the environment through thermal conduction, air change as well as short and long wave radiation. The maximum heating power of the implemented ideal heater is reasonably limited to $30 \mathrm{MW}$. A previous study with measured heat consumption and weather data concludes that the maximum instantaneous heating load of the campus is around $23 \mathrm{MW}$. 


\subsection{District Heating Network}

The district heating network's design is based on the information collected about the buildings' contracted heating power, the buildings' installations and their current operating temperatures. The DHN has been designed following a standard methodology (Krimmling 2011). The proposed district network has a tree structure and is simplified following the aggregation method described in Larsen et al. (2001). This method allows calculating the global heat loss and energy transport delay but not the pressure loss. The method has shown good results even after taking strong assumptions and extreme simplification of the distribution networks (Larsen et al. 2001, 2003). One of the strongest assumptions used by the aggregation method is that the ratio between mass flow rates in a pipe-branch is constant and proportional to the nominal power of the downstream consumer's nominal mass flow rate. Under this assumption the DHN is simplified step by step and the consumption points with it. Thus, once the DHN is reduced to one pipe/substation there is no need to redistribute the total energy demand of the city district between the different consumption points. In the present model the number of pipes was reduced from 75 to 1 .

The thermal pipe model itself consists of a water volume with a lumped heat capacity from the pipe's metal and a heat transfer model that computes the heat transfer between pipe and surroundings. The heat transfer model for district heating pipes is described with equations (14) and (15) (Bøhm 2000).

$$
\begin{aligned}
& \dot{Q}_{\mathrm{s}}=\left(U_{1}-U_{2}\right)\left(T_{\mathrm{s}}-T_{\mathrm{g}}\right)+U_{2}\left(T_{\mathrm{s}}-T_{\mathrm{r}}\right) \\
& \dot{Q}_{\mathrm{r}}=\left(U_{1}-U_{2}\right)\left(T_{\mathrm{r}}-T_{\mathrm{g}}\right)-U_{2}\left(T_{\mathrm{s}}-T_{\mathrm{r}}\right)
\end{aligned}
$$

$T_{\mathrm{S}}, T_{\mathrm{g}}$ and $T_{\mathrm{r}}$ stand for supply, undisturbed ground and return temperature respectively. $U_{1}$ is the overall length-specific coefficient of heat transfer (HTC) between the pipe and the environment. $U_{2}$ is the HTC between the supply and return pipe. They are described by equation (16) and (17).

$$
\begin{aligned}
U_{1} & =\frac{R_{\mathrm{g}}+R_{\mathrm{i}}}{\left(R_{\mathrm{g}}+R_{\mathrm{i}}\right)^{2}-R_{\mathrm{m}}^{2}} \\
U_{2} & =\frac{R_{\mathrm{m}}}{\left(R_{\mathrm{g}}+R_{\mathrm{i}}\right)^{2}-R_{\mathrm{m}}^{2}}
\end{aligned}
$$

The values of the ground thermal resistance $R_{\mathrm{g}}$, the thermal resistance of insulation and casing $R_{\mathrm{i}}$, and the thermal resistance associated to the interaction between the two pipes $R_{\mathrm{m}}$, can be found in Bøhm (2000).

For the calculation of heat flows it is assumed that the heat exchange between supply and return pipes is very low, $U_{1} \gg U_{2}$. Hence, the right terms in equation (14) and (15) are neglected, leading to a simpler equation. Furthermore the heat conductivity of the ground and isolation material are kept constant.
The undisturbed ground temperature, $T_{\mathrm{g}}$, at a depth $z$ at time $t$ is calculated with the equation (18) (Kusuda $\&$ Achenbach 1965). Here $\bar{T}$ is the mean temperature of the ground surface for the entire year, $A$ the annual amplitude of the ground surface temperature, $t_{0}$ a time shift that corresponds to the time at which the surface ground temperature has its minimum value, $\bar{T}-A$, and $\alpha$ is the thermal diffusivity of the soil. Equation (18) assumes a sinusoidal surface temperature with an oscillation period of one year. For the simulation, the time shift $t_{0}$ is set to 180 days and the equation is evaluated at the center of the pipe, $z=1 \mathrm{~m}$.

$T_{\mathrm{g}}(z, t)$

$$
=\bar{T}+A \mathrm{e}^{\left(-z \sqrt{\frac{\pi}{365 \mathrm{~d} \cdot \alpha}}\right)} \cos \left(\frac{2 \pi}{365 \mathrm{~d}}\left(t-t_{0}-\frac{z}{2} \sqrt{\frac{365 \mathrm{~d}}{\pi \alpha}}\right)\right)
$$

The pipe model is parameterized with a length 781 $\mathrm{m}$ and an overall length-specific HTC $U_{1}=$ $0.42 \mathrm{~W} / \mathrm{mK}$. The pipe is discretized in five elements.

\section{Simulation}

The modeling and simulations of the proposed system are mainly conducted to study the interaction between subsystems and towards a correct dimensioning of the different subsystems.

\subsection{System under simplified weather conditions}

For the simulation, in order to facilitate understanding of the system's behavior, simplified boundary conditions are used to create a seasonal behavior free of daily variations. Hence, synthetic weather data was defined with a sinus curve with a period of one year for the ambient temperature and an amplitude of $25^{\circ} \mathrm{C}$. Solar irradiation was neglected.

The simulation has been run for a period of eight years in Dymola using the solver DASSL with a tolerance value of $10^{-5}$.

Like Figure 1, Figure 7 shows the fluctuating thermal energy demand (negative values) and production (positive values) of the different subsystems.

At the beginning of the simulation the ATES has not been charged yet. Hence the AHT cannot be switched on and the district's thermal energy demand is covered by the CHP and the boiler. Later, when the thermal energy demand falls below CHP's thermal energy production, the surplus energy is used to charge the ATES. Thus, in the next heating period there is thermal energy stored in the aquifer, which can be used via the AHT until the fluid temperature from the aquifer reaches a certain minimum value at which the characteristic temperature difference $\Delta \Delta T$ is smaller than its selected minimum value (see 2.4).

The cycle repeats in the following years with the AHT operating period as well as the amount of thermal energy produced extending as shown in Table 2. 


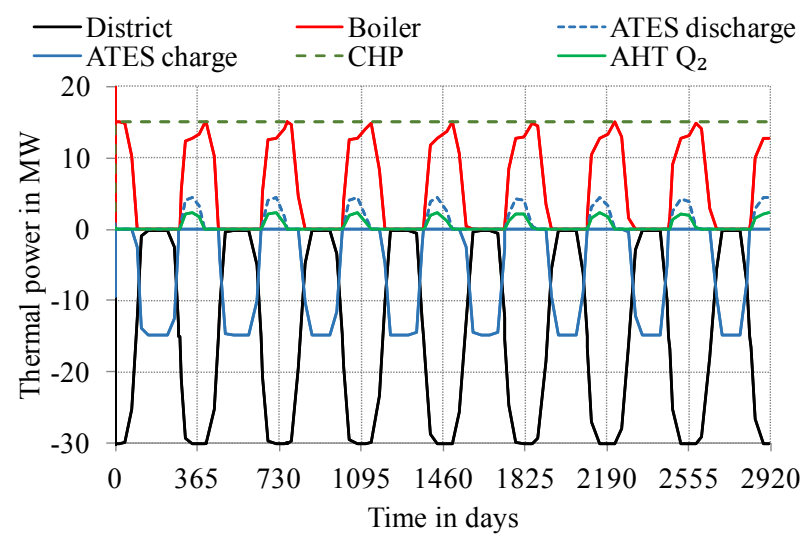

Figure 7. Thermal energy produced (positive values) and used by the different subsystems: Absorption heat transformer (AHT), combined heat and power plant (CHP), boiler, aquifer thermal energy storage (ATES) and district.

Table 2. AHT operation time in hours and energy produced in MWh after each seasonal discharge cycle.

\begin{tabular}{|c|c|c|}
\hline $\begin{array}{c}\text { Discharge } \\
\text { cycle }\end{array}$ & $\begin{array}{c}\text { AHT's operation } \\
\text { time in hours }\end{array}$ & $\begin{array}{c}\text { AHT's Energy } \\
\text { produced in MWh }\end{array}$ \\
\hline 1 & 2477 & 4511 \\
\hline 2 & 2554 & 4764 \\
\hline 3 & 2568 & 4770 \\
\hline 4 & 2580 & 4775 \\
\hline 5 & 2588 & 4780 \\
\hline 6 & 2596 & 4784 \\
\hline 7 & 2602 & 4788 \\
\hline
\end{tabular}

The AHT operation phase extends because the amount of thermal energy in the warm well after each charge cycle increases during the warm-up phase. The warm well injection temperature is limited to $T_{\text {inj }}^{\max }=60{ }^{\circ} \mathrm{C}$ and the initial aquifer temperature is $20^{\circ} \mathrm{C}$, while the AHT extracts heat with a rather small temperature difference of $15 \mathrm{~K}$. Hence, the stored heat is not recovered completely and the cold well injection temperature is much higher than the initial aquifer temperature until the cold side is warmed up. It means that during the warm-up phase, the extracted fluid from the cold well and reinjected through the warm well into the aquifer undergoes a smaller temperature. Hence more mass is heated up to the injection temperature than the previous charge cycle. Thus the thermal energy stored into the warm well increases year after year until the warm-up phase is over.

Figure 8 shows the ratio of recovered heat $Q_{\text {out }}$ to injected heat into the aquifer $Q_{\text {in }}$ for different injection temperatures $T_{\mathrm{inj}}$ in the warm well, calculated as heat recovery factor (HRF) by the following equation (Kranz \& Bartels 2009):

$\operatorname{HRF}\left(\tau_{i}\right)=\frac{Q_{\text {out }}}{Q_{\text {in }}}=\frac{\int_{0}^{\tau_{i}} \min \left(0, \dot{m}_{\mathrm{w}}\right) \cdot\left(h_{\mathrm{w}}-h_{\mathrm{c}}\right) d t}{\int_{0}^{\tau_{i}} \max \left(0, \dot{m}_{\mathrm{w}}\right) \cdot\left(h_{\mathrm{w}}-h_{\mathrm{c}}\right) d t}$ $\dot{m}_{\mathrm{w}}$ is the mass flow rate into the warm well, $h_{\mathrm{w} / \mathrm{c}}$ is the specific fluid enthalpy at the warm/cold well head. $\tau_{i}$ is the end time of the i-th discharge cycle.

The HRF is between 0 and 1 if the warm well temperature is always above cold well temperature and the cold well injection temperature is above the initial aquifer temperature.

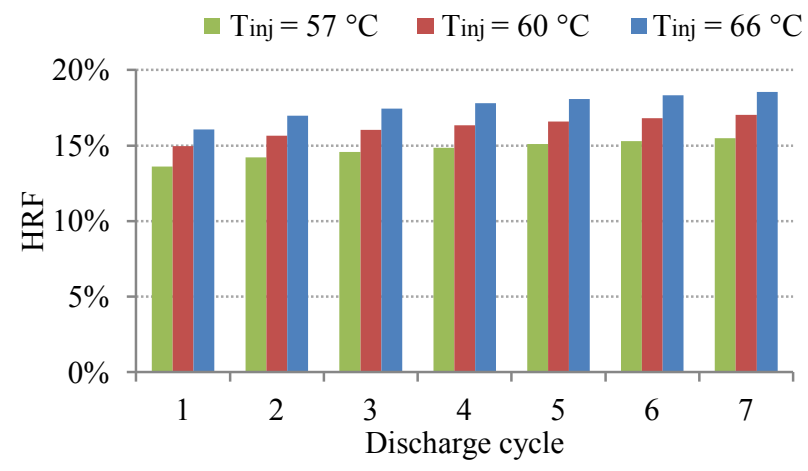

Figure 8. Aquifer heat recovery factor (HRF) for different injection temperatures $\boldsymbol{T}_{\mathbf{i n j}}$ in the warm well.

As explained above, the HRF increases over time because the cold side of the aquifer is warmed up in the first cycles. This is a common behavior of an ATES system. Furthermore, a higher injection temperature yields higher recovery factors.

\subsection{System under real weather conditions}

Simulating the system with synthetic weather boundary conditions, as described above, is vital for the fundamental understanding of the functionality of the described, complex system. However, to deduce meaningful results for real-world applications, the system model has to be simulated with actual weather input.

Usually real weather data used as input for simulations has larger gradients than synthetic, sinusoid weather data, as well as hourly spacing of samples, which requires interpolation.

Simulations with actual, measured weather data and the described system model have been performed successfully. Results will be presented in subsequent publications.

\section{Discussion}

The simulation results with simplified boundary conditions show that the stored energy cannot be used completely to drive the AHT, which yields low values of HRF. It is caused by a relatively high minimum value of the driving temperature $T_{1}$ over which the AHT can operate. This minimum temperature is obtained from equation (9) evaluated at $\Delta \Delta T=$ $\Delta \Delta T_{\min }=3{ }^{\circ} \mathrm{C}$ and specific values of $T_{0}$ (see Figure 9).

Figure 9 shows that in order to use low values of the AHT's driving temperature $T_{1}$, temperatures $T_{0}$ and $T_{2}$ must be low as well. $T_{0}$ is related to the ambient temperature (see chapter 2.4), in this regard it is 
interesting to favour the utilization of the AHT during the coldest months and at night. The minimum value $T_{2}$ is determined by the temperature range of the DHN. In this regard, low temperature DHN are favourable. Furthermore, the AHT should preheat the fluid before the CHP brings it to the temperature required by the DHN.

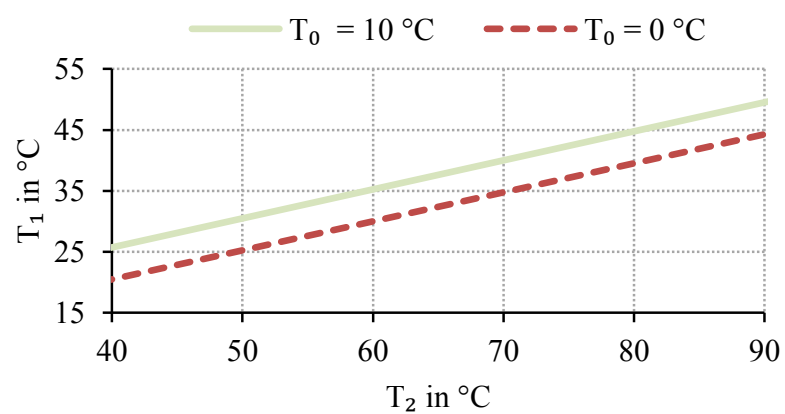

Figure 9. Minimum value of $T_{1}$ in dependency of $T_{2}$ for two different values of $T_{0}$ assuming $\Delta \Delta T_{\min }=3{ }^{\circ} \mathrm{C}$ and $B=1.1$.

The simulation results also show that the cold side of the aquifer needs several cycles to reach stable conditions. In order to shorten this warm-up phase with low HRF, it would be interesting to use a low cold well injection temperature so that less energy is needed warming up the cold side of the aquifer. Alternatively, one could reduce the distance between cold and warm well (Kranz et al. 2015). Modeling the interaction of the two wells would require a more detailed 2D/3D model for the aquifer.

Furthermore, the results show how a higher injection temperature yields higher HRF. In this regard, it is important to properly asses which is the upper temperature limit for safe operation of the ATES. Furthermore, if the warm well production temperature is sufficiently high to be used for preheating the return temperature of the DHN, this direct heat transfer is recommended.

The results obtained with real weather data highlights the importance of a correct sizing of the CHP. An oversized CHP reduces and shorts the period of times in which the AHT can work, causing the system to recover just part of the stored energy in the aquifer, thus obtaining low HRF. On the other hand, too small CHP produces less surplus energy and can make the utilization of an ATES system a nonsense.

\section{Conclusions and Future Work}

Modelica proved to be a proper framework for the development of models for the different subsystems by different research group as well as for their subsequent integration in a more complex model thanks to the use of common interfaces. Furthermore, Modelica and DYMOLA proved suitable for simulation of complex energy systems.

The simulation results show the expected thermal behavior of the different subsystems.
Different factors limiting the efficiency of the ATES system were pointed out. In this regard, a possibility to increase the HRF of the ATES was proposed.

Furthermore, the benefit of seasonal storage is shown as in the case study heat is recovered from the ATES which would otherwise have been lost as waste heat. Assessing the low values of the calculated HRF one has to allow for the simplified system design with simple boundary conditions, which has a lot of potential for improvement.

We are working towards the modeling of a more sophisticated system, including cooling demand, heat demand at different temperature levels and its pertinent distribution networks. Furthermore, we envisage increasing the level of modeling detail by adding new models for solar production, absorption heat pump type I and an absorption chiller, a as well as a 2D/3D aquifer model and more sophisticated control strategy.

\section{Acknowledgements}

The research described in this article is conducted within the research project ATES: Aquifer Thermal Energy Storage (Effizienz und Betriebssicherheit von Energiesystemen mit saisonaler Energiespeicherung in Aquiferen für Stadtquartiere) funded by the Federal Ministry for Economic Affairs and Energy in Germany (BMWi 03ESP409A/B/C).

\section{Nomenclature}

A

AHT

ATES

$B$

CHP Combined Heat and Power

COP Coefficient Of Performance

DHN District Heating Network

D

Dispersion length

$H \quad$ Thickness of the aquifer

HRF Heat Recovery Factor

HTC Heat Transfer Coefficient

HX Heat exchanger

$Q_{\mathrm{X}} \quad$ Heat

$\dot{Q}_{\mathrm{X}} \quad$ Heat flow rate

$P \quad$ Porosity

$R_{\mathrm{g}}$

Ground's thermal resistance

$R_{\mathrm{i}} \quad$ Insulation's thermal resistance

$R_{\mathrm{m}} \quad$ Thermal resistance between pipes

$\bar{T} \quad$ Mean annual temperature

$T \quad$ Temperature
K
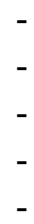

$\mathrm{m}$

$\mathrm{m}$

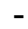

$-$

$\mathrm{kWh}$

$\mathrm{kW}$

$\frac{\mathrm{m}^{3}}{\mathrm{~m}^{3}}$

$\mathrm{mK}$

$\mathrm{mK}$

$\overline{\mathrm{W}}$

$\frac{\mathrm{mK}}{\mathrm{W}}$

$\mathrm{K}$

K 


\begin{tabular}{|c|c|c|}
\hline$U_{1}$ & Overall length-specific HTC & $\frac{\mathrm{W}}{\mathrm{mK}}$ \\
\hline$U_{2}$ & $\begin{array}{l}\text { Overall length-specific HTC } \\
\text { between supply and return pipe }\end{array}$ & $\frac{\mathrm{W}}{\mathrm{mK}}$ \\
\hline$c_{p}^{\mathrm{f}} / c_{p}^{\mathrm{s}} / \overline{c_{p}}$ & $\begin{array}{l}\text { Specific heat capacity of } \\
\text { fluid/rock/bulk }\end{array}$ & $\frac{\mathrm{J}}{\mathrm{kgK}}$ \\
\hline$h_{\mathrm{w} / \mathrm{c}}$ & $\begin{array}{l}\text { Specific fluid enthalpy at the } \\
\text { warm/cold well head }\end{array}$ & $\frac{\mathrm{J}}{\mathrm{kgK}}$ \\
\hline$r_{\mathrm{if}}$ & Radius of interface well/aquifer & $\mathrm{m}$ \\
\hline$r_{\infty}$ & Radius of outer aquifer boundary & $\mathrm{m}$ \\
\hline$S$ & Slope parameter & $\frac{\mathrm{W}}{\mathrm{K}}$ \\
\hline$t$ & Time & $\mathrm{s}$ \\
\hline$t_{0}$ & Time shift & $\mathrm{d}$ \\
\hline$k$ & Rock thermal conductivity & $\frac{\mathrm{W}}{\mathrm{mK}}$ \\
\hline$k_{\text {eff }}$ & Effective thermal conductivity & $\frac{\mathrm{W}}{\mathrm{mK}}$ \\
\hline$\dot{m}$ & Mass flow rate into the well & $\frac{\mathrm{kg}}{\mathrm{s}}$ \\
\hline$u$ & Darcy flux/velocity & $\frac{\mathrm{m}}{\mathrm{s}}$ \\
\hline$z$ & Depth & $\mathrm{m}$ \\
\hline$\alpha$ & Thermal diffusivity & $\frac{\mathrm{m}^{2}}{\mathrm{~d}}$ \\
\hline$\Delta \Delta T$ & $\begin{array}{l}\text { Characteristic temperature } \\
\text { difference }\end{array}$ & $\mathrm{K}$ \\
\hline$\Delta \Delta T_{\min , \mathrm{X}}$ & Loss parameter & $\mathrm{K}$ \\
\hline$\rho^{\mathrm{f}} / \rho^{\mathrm{s}} / \bar{\rho}$ & Density of fluid/rock/bulk & $\frac{\mathrm{kg}}{\mathrm{m}^{3}}$ \\
\hline$\tau_{i}$ & End time of i-th discharge cycle & $S$ \\
\hline
\end{tabular}

Appendix - Discretized heat transfer equation

The equation by Bear \& Bachmat (1990) was formulated in polar coordinates and reduced to the radial component to yield eq. (1), which describes the conductive-convective transient radial heat flow in porous media:

$$
\rho c_{p} \frac{\partial \mathrm{T}}{\partial \mathrm{t}}=\frac{1}{r} \frac{\partial}{\partial r} k_{\mathrm{eff}} r \frac{\partial T}{\partial r}-\rho^{\mathrm{f}} u c_{p}^{\mathrm{f}} \frac{\partial T}{\partial r} .
$$

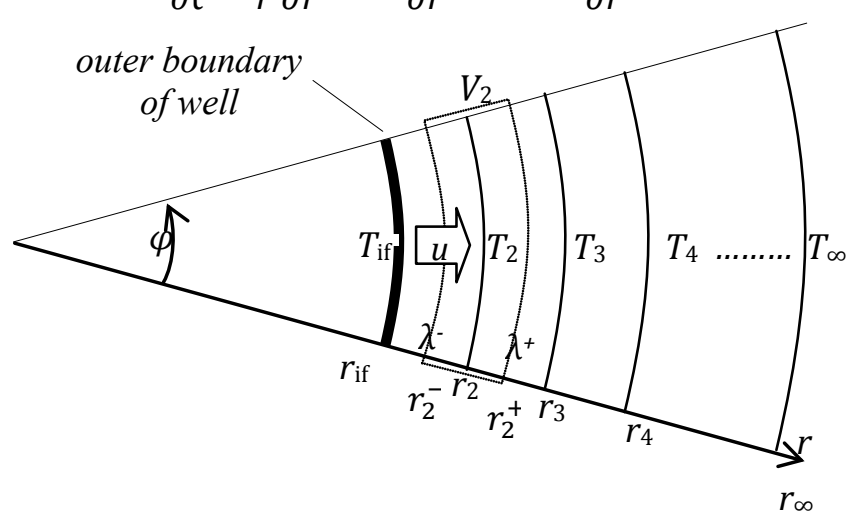

Figure 10. Radially equidistant discretization of aquifer
In order to solve eq. (1) numerically, the radially symmetric aquifer was subdivided in equidistant sections as shown in Figure 10 and the equation was discretized as follows.

First, it is integrated over the ring segment $V$ assuming constant $\rho, c_{p}$ and $\rho^{\mathrm{f}}$ :

$$
\begin{aligned}
\int_{V} \bar{\rho} \overline{c_{p}} \frac{\partial T_{i}}{\partial t} d V & =\int_{V}\left(\frac{1}{r} \frac{\partial}{\partial r} k_{\mathrm{eff}} r \frac{\partial T}{\partial r}-\rho^{\mathrm{f}} u c_{p}^{\mathrm{f}} \frac{\partial T}{\partial r}\right) r d \varphi d r d z \\
\bar{\rho} V \overline{c_{p}} \frac{\partial T_{i}}{\partial t} & =2 \pi H \int_{r_{-}}^{r_{+}}\left(\frac{\partial}{\partial r} k_{\mathrm{eff}}^{i} r \frac{\partial T}{\partial r}-\rho^{\mathrm{f}} u r c_{p}^{\mathrm{f}} \frac{\partial T}{\partial r}\right) d r .
\end{aligned}
$$

By substituting $\rho^{\mathrm{f}} u H 2 \pi r=\dot{m}$ one obtains

$$
\bar{\rho} V \overline{c_{p}} \frac{\partial T_{i}}{\partial t}=\left.\left(2 \pi H k_{\mathrm{eff}} r \frac{\partial T}{\partial r}-\dot{m} c_{p} T\right)\right|_{r^{-}} ^{r_{+}} .
$$

Finally, the discretized equation is obtained using the symmetric first order difference quotient and an upstream velocity scheme for the convective term:

$$
\begin{aligned}
& \bar{\rho} V \overline{c_{p}} \frac{\partial T_{i}}{\partial t}=2 \pi H k_{\text {eff }}\left(r_{+} \frac{T_{i+1}-T_{i}}{r_{i+1}-r_{i}}-r^{-} \frac{T_{i}-T_{i-1}}{r_{i}-r_{i-1}}\right) \\
& -\dot{\mathrm{m}} c_{p}\left\{\begin{array}{l}
T_{i+1}-T_{i} \text { if } u<0 \\
T_{i}-T_{i-1} \text { if } u>0
\end{array},\right.
\end{aligned}
$$

where $V=2 \pi r H, k_{\text {eff }}$ and $u$ are functions of $r$ and hence segment specific (index $i$ has been omitted for brevity). $\bar{\rho}, \overline{c_{p}}$ and $k$ may be varying or constant.

\section{References}

Albers, J., Kuehn, A., Petersen, S., \& Ziegler, F.Control of absorption chillers by insight: the characteristic equiation. Krakau. 2008

Bear, J., \& Bachmat, Y.Introduction to modeling of transport phenomena in porous media, Vol. 4. Springer Science \& Business Media. 1990

Bøhm, B.On transient heat losses from buried district heating pipes. International journal of energy research. 2000

Cudok, F., \& Ziegler, F.Absorption heat converter and the charakteristic equation method. International Congress of Refrigeration. Yokohama, Japan. 2015

Dinçer, I., \& Rosen, M. A.Thermal Energy Storage: Systems and Applications. John Wiley \& Sons, Ltd. 2002

Inderfurth, A., Nytsch-Geusen, C., \& Ribas Tugores, C.Parameter identification for low-order building models using optimization strategies. 14th international Conference of the Building Performance Simulation Association (IBPSA). Hyderabad, India. 2015

Kranz, S., \& Bartels, J.Simulation and data based identification of parameters affecting seasonal ATES efficiency. Effstock 2009, pp. 1-8. Stockholm, Sweden. 2009

Kranz, S., Bloecher, G., \& Saadat, A.Improving Aquifer Thermal Energy Storage Efficiency. World Goethermal Congress. 2015

Krimmling, J.Energieefiziente

Nahwärmesysteme. Fraunhofer IRB. 2011 
Kusuda, T., \& Achenbach, P. R.Earth temperature and thermal diffusivity at selected stations in the united states. National Bureau of Standards Gaithersburg MD. 1965

Larsen, H. V., Bøhm, B., \& Wigbels, M.A comparison of aggregated models for simulation and operational optimisation of district heating networks. Energy Conversion \& Management. 2003

Larsen, H. V., Pálsson, H., Bøhm, B., \& Ravn, H. F.Aggregated Dynamic simulation model of district heating networks. Energy Conversion \& Management. 2001

Modelica-Association.Modelica Standard Library. 2014

Nytsch-Geusen, C. Modelica Library Building Systems. 2014

Puig-Arnavat, M., L-pez-Villada, J., Bruno, J. C., \& Coronas, A.Analysis and parameter identification for characteristic equations of single- and doubleeffect absorption chillers byÊmeans of multivariable regression. International Journal of Refrigeration, 33/1: 70-78. 2010 . DOI: http://dx.doi.org/10.1016/j.ijrefrig.2009.08.005

Sanner, B., Kabus, F., Seibt, P., \& Bartels, J.Underground Thermal Energy Storage for the German Parliament in Berlin, System Concept and Operational Experiences. World Geothermal Congress 2005. Antalya, Turkey. 2005

Schmidt, T., Kabus, F., \& Müller-Steinhagen, H.The Central Solar HHeati PLant with Aquifer Thermal Energy Store in Rostock, Germany. TERRASTOCK. Stuttgart, Germany. 2000

Wetter, M., \& Treeck, C. van.IEA EBC Annex 60, New generation computational tools for building and community energy systems based on the Modelica and Functional Mockup Interface standards. 2014 